\title{
THE USE OF MODIFIED SUGARCANE BAGASSE IN NATURAL RUBBER COMPOUNDING
}

\author{
A.K. Akinlabi ${ }^{1}$, R.N. Laleye ${ }^{1 *}$, S. B. Akinfenwa ${ }^{1}$, A.M, Mosaku ${ }^{1}$, F. Akinwunmi ${ }^{1}$, A. A. Falomo ${ }^{1}$, G. \\ Oladipo $^{1,2}$, S. O. Oni ${ }^{1,3}$, F. Y Falope ${ }^{1,4}$, N. Y Ilesanmi ${ }^{1}$, T. O. Aborode and T. D. Idowu ${ }^{1}$ \\ ${ }^{1}$ Industrial Chemistry Unit, Dept. of Chemistry, Federal Univ. of Agriculture, Abeokuta. \\ ${ }^{2}$ Science Laboratory Tech Dept., D.S Adegbenro ICT Polytechnic, Itori, Ogun State. \\ ${ }^{3}$ Chemistry Unit, Faculty of Physical Sciences, Lead City University, Ibadan, Oyo State. \\ ${ }^{4}$ Dept. of Chemistry, The Bells University, Otta, Ogun State \\ *Corresponding author- rachaellaleleye@gmail.com Tel- +2348067923201 \\ Received 11 September 2020; accepted 15 October 2020, published online 30 October 2020
}

\section{ABSTRACT}

Natural rubber (NR) is a renewable agricultural resource which has gained fast technological innovation due to some inherent properties and its renewability. Compounding of natural rubber with modified and unmodified nanosized agricultural waste is of interest because it is economical, environmentally friendly, cheap and readily available, hence, the trial of sugarcane bagasse as an additive in Natural Rubber compounding. The sugarcane bagasse was sourced locally, milled to fine powder and sieved to $<100 \mu \mathrm{m}$ in size. Characterization of Natural rubber latex viz-a-viz: Dry rubber content (DRC), Total solid content (TSC), Ash content, Moisture content were carried out. The Sugarcane bagasse was modified via Hydroxylation using 10\% Sodium hydroxide $(\mathrm{NaOH})$. The modified sugarcane baggase (MSB) and unmodified sugarcane baggase (USB) were characterized viz-a-viz: their $\mathrm{pH}$, moisture content, Fourier transform infrared spectroscopy and micro-pixe analysis. The extent of modification was determined via titration. The NR was thereafter compounded with USB, MSB, CB, admix of MSB with CB and admix of USB with $C B$ to give five vulcanizates, labeled $A-E$ ( $A-40$ parts $C B$, B- 40 parts USB, C- 40 parts MSB, D- 20 CB : 20 USB while E was $20 \mathrm{CB}: 20 \mathrm{MSB}$ ). The vulcanizates were then subjected to physicomechanical tests viz-a-viz: Tensile strength, Modulus Elasticity, Hardness, Elongation @ break and Yield elongation. The result revealed that mix A (control) with $40 \mathrm{CB}$ has the highest Tensile strength compared to the other mixes, which was followed by mixes $\mathrm{E}>\mathrm{D}>\mathrm{C}$ while $\mathrm{B}$ gave the least tensile strength, showing that carbon black acted better than modified sugarcane bagasse and better than unmodified sugarcane bagasse. Compatibility of the unmodified and hydroxylated sugarcane bagasse with natural rubber and carbon black was also established. The extent of the solubility of the mixes in ethanol, kerosene and petrol were investigated to determine the extent of crosslinking and mix A was very resistant to all the solvents followed by mixes $\mathrm{C}$ then $\mathrm{E}$ then $\mathrm{D}$ while mix B dissolves readily.

KEYWORDS- Additives, sugarcane bagasse, compounding, blends, natural rubber, vulcanizates, solubility

\section{INTRODUCTION}

The economic importance of Natural Rubber Latex (NRL) cannot be overemphasized due to its wider application in technological uses[1].Natural rubber (NR) is a renewable agricultural resource that is commercially used due to its outstanding polymeric properties. It can be isolated from a number of different species of plants namely Hevea brasiliensis, Funtumia elastic, Landolphia species, Manihot glaziovii etc., but commercially Hevea brasiliensis has been the most exploited species[2]. In Hevea plant, natural rubber is contained in whitish milky liquid latex, which the plant exudes when a cut is made on the stem. Natural rubber on its own does not possess the necessary hardness and modulus required for commercial acceptability [2] but the incorporation of certain materials (compounding ingredients) will increase its characteristics to the level desired for natural rubber (NR) demand and make it useful in the manufacture of desired materials such as hand gloves, foot mats, tyres, shoe soles, buttons, conveyor belts, transmission belts, tubes etc [2]. 
Incorporation of various ingredients (additives) into natural rubber is known as compounding. In natural rubber compounding, various additives are added to enhance the processability and properties of the vulcanisates. The different types of additives used in the processing of rubber include, vulcanizing agents accelerator, activator, antidegradants, fillers, softener, thickeners, colorant e.t.c [3].

Natural rubber and synthetic rubber are converted to serviceable products by combining them with fillers [4]. Fillers are materials which when added to rubber mix enhance the properties. These properties are physical in nature which include hardness, tensile strength. Flex fatigue, stiffness and to some extent, the chemical properties. Fillers improve the processing characteristics, reduce cost and also acts as auxiliary components necessary for vulcanisate. Fillers can either be reinforcing, semi-reinforcing or non-reinforcing. Reinforcing fillers enhance the physical properties of the cured article. An example of this is carbon black, which in 1905 was discovered that fine particulate of carbon black included in rubber used on the outer part of a tyre almost doubled the lifespan of the tyre.

There are also non-reinforcing fillers. They reduce cost and improve processing characteristics for example by reducing nerve in the processing of rubber. Non-reinforcing fillers have little or no effect on the physical properties of the rubber [5]. They act as processing aid (which are cheap) by increasing the bulk of the products. Examples of these include talc, barites, mica powder, whiting and china clay. Semi-reinforcing fillers are partially reinforcing. These include soft clay, calcium carbonate and antimony. The mechanism of reinforcement of elastomers by fillers has been reviewed by several workers [2- 6]. They considered the effect of filler to increase the number of chains, which share the load of a broken polymer chain. Literature has also shown that the efficiency of reinforcement depends on a complex interaction of several filler related parameters. These include particle size, particle shape, particle dispersion, surface area, surface reactivity, structure of the filler and the bonding quality between the filler and the rubber matrix.

Bagasse is the fibrous matter that remains after sugarcane or sorghum stalks are crushed to extract their juice. It is a waste that is chewed from sugar cane and if discarded and start decaying, it attracts insects such as flies. If decaying in a moist environment, it produces an unpleasant smell or odour which attracts different types of insects. Though the cane fibre does not get decayed easily if it is in a very dry environment, the water is being evaporated by heat leaving the fibre dry, and after some days, it begins to form crumps, with these expression above, if sugar cane fibre is being preserved well as earlier stated, it could serve as filler in the compounding of natural rubber (NR) when properly grinded and sieved, this will make it useful and no longer constitute a waste or health hazard to the environment. The aim of this work is to assess the effects of modified sugarcane bagasse on properties of natural rubber vulcanisate. The fibre content of the sugarcane bagasse, its availability couple with its environmental friendliness serves as the basis for this study with the anticipation of converting it to a useful material in polymer technology, which will eventually reduce the production cost of products derived from it.

\section{EXPERIMENTAL MATERIALS}

Natural Rubber latex from NIG 902 clone, having the characteristics as shown in Table I, was obtained from the estates of the Rubber Research Institute of Nigeria, Benin City, Nigeria. The rubber latex was processed to crumb rubber in the laboratory which was then used for the compounding, the crumb rubber was characterized using Standard African Rubber Manual 2 of 1988 [2]. Chemicals used were obtained from the British Drug House (BDH) and used as supplied. 
Table 1; Showing the characteristics of the natural rubber latex used.

\begin{tabular}{ll}
\hline PARAMETERS & COMPOSITION (\%) \\
\hline Dry Rubber Content (DRC) & 36.26 \\
Total Solid Content (TSC) & 38.30 \\
Moisture Content & 56.67 \\
Ash Content & 2.13 \\
Mechanical Stability & 550 \\
\hline
\end{tabular}

Sugarcane bagasse for this research was obtained from papa village, Ogun state and was processed into powder using a hammer mill and burr mill through cutting and milling which was done at the Agricultural Engineering Department, FUNAAB. The sugarcane were crushed to extract the juice and to obtain the bagasse which was dried under the sun for three days after which the dried bagasse was ground into powder using a hammer and burr mill. It was then screened using a $<100 \mu \mathrm{m}$ mesh.

\section{METHODS}

\section{PREPARATION OF CRUMB RUBBER}

The natural rubber latex was transferred into a clean bowl and $5 \%$ acetic acid was added with continuous stirring until the rubber coagulates. It was then washed with distilled water and was cut into small pieces and was washed again with distilled water to remove any acid left. It was spread onto a foil paper and was then placed in a drying cabinet at $110{ }^{\circ} \mathrm{C}$ at 2-3 hours to obtain the crumb rubber.

\section{HYDROXYLATION OF SUGARCANE BAGASSE}

A $10 \%$ solution of $\mathrm{NaOH}$ was added into the sieved $5 \mathrm{~g}$ bagasse in a beaker. It was stirred and kept for 4 hours at room temperature. After 4 hours, the hydrolyzed sugarcane bagasse was washed with distilled water to remove excess of sodium hydroxide and finally dried in the oven at $105^{\circ} \mathrm{C}$.

\section{CHARACTERIZATION OF SUGARCANE BAGASSE}

Moisture content and $\mathrm{pH}$ test was carried out on the sugarcane bagasse to ascertain its utilization as additive in NR compounding.

\section{FOURIER TRANSFORM INFRARED (FT-} IR) SPECTROSCOPY ANALYSIS

This was done on the modified (hydroxylated) and unmodified sugarcane bagasse to determine the presence of $\mathrm{O}-\mathrm{H}$ group difference in both samples.

\section{MICROPIXE ANALYSIS}

This analysis was carried out to determine the elemental composition of the unmodified and modified (hydroxylated) sugarcane bagasse which is to be used as an additive in the compounding of Natural Rubber.

\section{RECIPE FOR COMPOUNDING}

Standard formulation for natural rubber compounding mix was adopted[2]. A typical formulation is as given in Table 2 below: 
Table 2: Compounding formulation for the vulcanizates.

\begin{tabular}{lccccc}
\hline $\begin{array}{l}\text { Compounding } \\
\text { ingredients. }\end{array}$ & $\begin{array}{c}\text { Mix A } \\
\text { (pphr) }\end{array}$ & $\begin{array}{c}\text { Mix B } \\
\text { (pphr) }\end{array}$ & $\begin{array}{c}\text { Mix C } \\
\text { (pphr) }\end{array}$ & $\begin{array}{c}\text { Mix D } \\
\text { (pphr) }\end{array}$ & $\begin{array}{c}\text { Mix E } \\
\text { (pphr) }\end{array}$ \\
\hline Natural rubber & 100 & 100 & 100 & 100 & 100 \\
Sulphur & 2.5 & 2.5 & 2.5 & 2.5 & 2.5 \\
TMQ & 1.5 & 1.5 & 1.5 & 1.5 & 1.5 \\
Zinc Oxide & 2.5 & 2.5 & 2.5 & 2.5 & 2.5 \\
Steric Acid & 2.5 & 2.5 & 2.5 & 2.5 & 2.5 \\
MBTS & 1.0 & 1.0 & 1.0 & 1.0 & 1.0 \\
Flectol H & 2.0 & 2.0 & 2.0 & 2.0 & 2.0 \\
Carbon Black & 40 & - & - & 20 & 20 \\
Unmodified & - & 40 & - & 20 & - \\
Bagasse & - & - & 40 & - & 20 \\
Modified Bagasse & - & - & & & \\
\hline
\end{tabular}

Mix $\mathrm{A}=$ Rubber with carbon black, Mix $\mathrm{B}=$ Rubber with unmodified bagasse, Mix $\mathrm{C}=$ Rubber with modified baggase, Mix D = Rubber with ummodified bagasse and carbon black, Mix E = Rubber with modified bagasse and carbon black

\section{Mechanical Properties}

The vulcanisates were moulded using a hydraulic compression machine (Saumya Technologies) at $150^{\circ} \mathrm{C}$ for five minutes. It was allowed to cool and was punched out of the mould for the mechanical tests. Tensile properties of the vulcanisates were measured using a Saumya Universal Instron Testing Machine at a crosshead speed of $500 \mathrm{~mm} / \mathrm{min}$ using a dumb bell specimen [7]. Thereafter, the tensile strength at break, modulus and elongation at break were recorded. The results are as shown in Table 5.

\section{Hardness Test}

The hardness of the vulcanisate was determined by adopting the standard dead load method[7]. The standard dead load method of measurement covers rubbers in the range of 30-85 International Rubber Hardness Degrees (IRHD). The results are as shown in Table 5.

\section{Swelling and solubility}

The resistance and rates at which the vulcanisates swell in ethanol, petrol and kerosene were determined in accordance with ASTM D3610. Three different shapes were cut from each of the test samples and the weights were recorded before submerging each sample in respective solvents in airtight beakers done by covering them with aluminium foils to prevent escape of solvents. This was done at room temperature. Experiments were carried out in triplicate using the test piece cut into triangle, square and circle shapes. At the end of the swelling, the samples were removed from the solvent, carefully blotted to remove excess liquid from the surface and the weights were immediately taken@ 2 hrs interval up to 24 hrs.

\section{RESULTS AND DISCUSSION}

The natural rubber latex obtained was characterized as shown in Table 1. The dry rubber content which gives the exact amount of rubber present was found to be $36.26 \%$ while the total solid content which gives the total amount of solid materials in the rubber latex was found to be $38.30 \%$. Total solid content is expected to be higher than the dry rubber content as was observed because dry rubber content is also embedded in the solids content of the rubber latex.

The moisture content of the fibre is $9.52 \%$. Moisture content is very important because fibre dimension and properties vary with it. High moisture absorption of natural fibres leads to swelling and presence of voids which results in poor mechanical properties and reduces dimensional stability of composites. The $\mathrm{pH}$ of the additive shows a $\mathrm{pH}$ of (6.10) which is alkaline, It is generally well known that acidic fillers retards the cure rate (longer cure time) while alkaline filler accelerates cure rate 
(shorter cure time) leading to poor mechanical

Table 3: Characteristics of the sugarcane Bagasse.

\begin{tabular}{ll}
\hline PARAMETER & PERCENT \\
\hline $\mathrm{Ph}$ & 6.10 \\
Moisture Content & 0.85
\end{tabular}

The FT-IR of Modified (Hydroxylated) Bagasse showed the presence of $\mathrm{O}-\mathrm{H}$ stretching vibration at a very close range between (35503200 ), a broad band which is due to the presence of free intermolecular hydrogen bond while the unmodified sugarcane bagasse showed N-H stretch at (3343.25). There were presence of $\mathrm{C}-\mathrm{H}$ stretch in all the above in a region of (3000-2840). There was absence of $\mathrm{S}=\mathrm{O}$ stretch in the unmodified sugarcane bagasse which was present in the modified. It occurred in the region of $(1415-1380)$. $\mathrm{C}=\mathrm{C}$ stretch was observed in the two spectral but the properties of natural rubber vulcanizates [8-9]. level of $\mathrm{C}=\mathrm{C}$ stretch in modified bagasse reduced. This could be as a result of the presence of $\mathrm{OH}$ group in the modified bagasse. C-O stretch was also observed in the two spectral. Basically, the effect of the modifications were reflected by the presence of $\mathrm{O}-\mathrm{H}$ functional groups observed in the modified when compared to the unmodified spectra.

\section{MICRO-PIXE ANALYSIS}

The result for the micro-pixe analysis showed that the value for Sodium $(\mathrm{Na})$ increase from 0.0018 for unmodified bagasse to 0.4356 for modified bagasse, Hydrogen $(\mathrm{H})$ increase from 0.0069 for unmodified bagasse to 0.0073 for modified bagasse and Oxygen $(\mathrm{O})$ increase from 0.0033 for unmodified bagasse to 0.0048 for modified bagasse. The above interpretation shows that there is increase in the hydrogen and oxygen value which make up the $\mathrm{OH}$-group.

Table 4: Micro-pixe result for unmodified and Hydroxylated Sugarcane Bagasse.

\begin{tabular}{|c|c|c|}
\hline Elements & $\begin{array}{l}\text { Unmodified Bagasse } \\
(\%)\end{array}$ & $\begin{array}{l}\text { Hydroxylated } \\
\text { Bagasse }(\%) \\
\end{array}$ \\
\hline $\mathbf{N a}$ & 0.0012 & 0.4356 \\
\hline Mg & 0.1130 & 0.0231 \\
\hline Al & 0.0406 & 0.0001 \\
\hline Si & 0.4130 & 0.2750 \\
\hline $\mathbf{F e}$ & 0.0589 & 0.0241 \\
\hline $\mathbf{S}$ & 0.1270 & 0.0315 \\
\hline $\mathbf{O}$ & 0.0033 & 0.0048 \\
\hline Cl & 0.1119 & 0.0293 \\
\hline $\mathbf{K}$ & 0.6196 & 0.1242 \\
\hline $\mathbf{C a}$ & 0.2801 & 0.2194 \\
\hline H & 0.0069 & 0.0073 \\
\hline Mn & 0.0049 & 0.0018 \\
\hline
\end{tabular}


Table 5: Physico- mechanical properties of vulcanisates

\begin{tabular}{|c|c|c|c|c|c|}
\hline PARAMETER & MIX A & MIX B & MIX C & MIX D & MIX E \\
\hline $\begin{array}{l}\text { Tensile } \\
\text { strength @ } \\
\text { breaking load } \\
\text { (MPa) }\end{array}$ & 10.7 & 10.3 & 10.4 & 10.2 & 10.1 \\
\hline $\begin{array}{l}\text { Elongation @ } \\
\text { break\% }\end{array}$ & 683 & 654 & 605 & 605 & 565 \\
\hline Hardness & 44 & 43 & 42 & 40 & 40 \\
\hline $\begin{array}{l}\text { Modulus } \\
\text { elasticity } \\
\text { (MPa) }\end{array}$ & 5.6 & 4.2 & 3.8 & 3.7 & 2.0 \\
\hline $\begin{array}{l}\text { Yield } \\
\text { elongation } \\
(\mathbf{m m})\end{array}$ & 30.50 & 26.80 & 20.00 & 17.30 & 3.80 \\
\hline
\end{tabular}

Mix A= Rubber with carbon black (40g) (control sample), Mix $\mathrm{B}=$ Rubber with unmodified bagasse (40g), Mix C= Rubber with modified baggase (40g), Mix D = Rubber with ummodified bagasse(20g) and carbon black(20g), Mix E = Rubber with modified bagasse (20g) and carbon black (20g)

TENSILE STRENGTH: It reflects the average strength of the vulcanizate when it is put to use. Tensile strengths are generally governed by filler dispersion, particle size, specific surface area of filler and rubber interaction[2]. The tensile value in table 5 varied from $10.7 \mathrm{MPa}$ in $40 \mathrm{~g}$ carbon black, $10.4 \mathrm{MPa}$ for $20 \mathrm{~g}$ carbon black and $20 \mathrm{~g}$ modified sugarcane bagasse substituted, 10.3 MPa for $20 \mathrm{~g} \mathrm{CB}$ and $20 \mathrm{~g}$ unmodified bagasse substituted, 10.2 MPa for $40 \mathrm{~g}$ hydroxylated bagasse substituted and $40 \mathrm{~g}$ for unmodified bagasse substituted. The trend in this result shows that as the level of bagasse increases, the tensile strength reduces, signifying that bagasse has not enhanced strength reinforcement. Looking at the extent of reduction from mix A $40 \mathrm{~g} \mathrm{CB}$ to mix B $40 \mathrm{~g}$ USB, there was $2.8 \%$ reduction, for mix C, there was $3.7 \%$ reduction, mix $\mathrm{D}$ gave $4.7 \%$ reduction and mix $\mathrm{E}$ gave $5.6 \%$ reduction. Comparing mix A, which has a high level carbon black with the other mixes, mix A has higher value of tensile strength compared to the other mixes. Also, comparing the tensile values of unmodified with hydroxylated bagasse of the same substitution level, it was observed that hydroxylated bagasse generally have higher values than the unmodified bagasse, signifying that hydroxylated bagasse will increase the tensile more than unmodified sugarcane bagasse. Technologically, the least standard accepted tensile strength for a Natural rubber mix is around 7.5 $\mathrm{MPa}$. Observing the tensile strength obtained for all the mixes in Table 5, it can be seen that the results are still within the accepted technologically permitted level.

ELONGATION @ BREAK: It shows the extent of flexibility of the material at a specific applied force. Comparing the elongation values of other mixes in table 5, mix A which is the control sample with high level of carbon black has higher value of elongation (683\%). Also, comparing the elongation values of hydroxylated bagasse with unmodified bagasse in Table 5, it was observed that the hydroxylated bagasse have higher value of elongation than the unmodified sugarcane bagasse. Generally, the result of elongation @ break were found reducing from mix $\mathrm{A}-\operatorname{mix} \mathrm{E}$ and supports softening properties of the sugarcane bagasse. The incorporation of $\mathrm{CB}$ with hydroxylated sugarcane bagasse does not produce a drastic reduction in the tensile strength, meaning that the modification of the bagasse via hydroxylation gives an appreciable result when used as additives and might serve as an effective way of converting an agricultural waste into a useful product.

HARDNESS: It shows the resistance of the vulcanizate to indentation. A high hardness value signifies a well cross linked material[8]. In Table 5 , comparing all the mixes, mix A with higher 
level of carbon shows higher value of hardness and comparing the hardness values of mix B- mix $\mathrm{E}$, it was observed that mix $\mathrm{B}$ with incorporation of carbon black and hydroxylated bagasse have higher hardness value, which implies that carbon black and its incorporation with hydroxylated bagasse for natural rubber compounding formed more networks than the sugarcane bagasse only.

MODULUS ELASTICITY: It is the behaviour of the material. The result of modulus also follows the trend of elongation@ @reak. The effect of carbon black in natural rubber compounding increases the values of physicomechanical properties than that of hydroxylated and unmodified sugarcane bagasse only, because $\mathrm{CB}$ is a reinforcing filler. Although, it was observed that the hydroxylated bagasse have higher value of physico-mechanical properties than the unmodified bagasse. Akinlabi et al [2] commented on influence of additives on physical properties of vulcanizates, where he stated that the addition of any particulate filler can reduce some of the physical parameter of a polymer more or less in proportion to the volume present. The only exception to this is carbon black in rubbers, which have hydrocarbon in the main chain structure and fibrous fillers. Fibrous fillers behave exceptionally whenever their volume loading is sufficiently high, the length to diameter ratios are sufficiently large, and the fibres themselves are strong. Hence this will influence the physic-mechanical properties of vulcanizate because the parameters will be determined almost wholly by the fibre or filament participating in the crosslinking network formation. It can therefore be justified from the results in Table 5 that the hydroxylated and unmodified sugarcane bagasse will find uses as additives in materials where strength reinforcing is not of paramount interest or when combining it with carbon black.

\section{CHEMICAL BEHAVIOUR HAS SHOWN BY SWELLING AND SOLUBILITY RESULT}

Swelling and solubility of natural rubber has been documented by Baker et al [10] to be influenced by various factors, such as crosslink type and density, amount, nature and type of compounding ingredients and of elastomer. The extent of the solubility of the vulcanizates in ethanol, kerosene and petrol were investigated to determine the extent of crosslinking and mix A was very resistant to all the solvents followed by mix B which dissolves readily. The solvent kerosene dissolves readily in all vulcanizates followed by the petrol while ethanol dissolves slightly. 
Table 6: Swelling and solubility results of the vulcanisates in different solvents

\begin{tabular}{|c|c|c|c|c|c|c|}
\hline SOLVENT & $\begin{array}{l}\text { TIME } \\
\text { INTERVA } \\
\text { L }\end{array}$ & MIX A & $\begin{array}{l}\text { MIX } \\
\text { B }\end{array}$ & MIX C & MIX D & MIX E \\
\hline ETHANOL & $\begin{array}{l}\text { Initial } \\
\text { weight (g) } \\
@ 2 \mathrm{hrs} \\
@ 4 \mathrm{hrs} \\
@ 6 \mathrm{hrs} \\
@ 8 \mathrm{hrs} \\
@ 24 \mathrm{hrs}\end{array}$ & \begin{tabular}{l|l|}
0.9 \\
\\
1.0 \\
1.0 \\
1.0 \\
1.0 \\
1.2
\end{tabular} & $\begin{array}{l}0.6 \\
\\
0.6 \\
0.7 \\
0.7 \\
0.7 \\
0.9\end{array}$ & $\begin{array}{l}0.9 \\
\\
0.9 \\
0.9 \\
1.0 \\
1.0 \\
1.1\end{array}$ & \begin{tabular}{l|}
0.9 \\
\\
0.9
\end{tabular} & $\begin{array}{l}0.8 \\
\\
0.8 \\
0.8 \\
0.8 \\
0.9\end{array}$ \\
\hline $\begin{array}{l}\text { KEROSEN } \\
\text { E }\end{array}$ & $\begin{array}{l}\text { Initial } \\
\text { weight (g) } \\
\text { @ } 2 \text { hrs } \\
\text { @ } 4 \text { hrs } \\
\text { @ } 6 \text { hrs } \\
\text { @ } 8 \mathrm{hrs} \\
\text { @ } 24 \mathrm{hrs}\end{array}$ & $\begin{array}{l}0.8 \\
\\
2.0 \\
2.4 \\
2.4 \\
2.3 \\
\text { Slurry }\end{array}$ & $\begin{array}{l}\mathbf{0 . 8} \\
\\
2.3 \\
2.7 \\
2.9 \\
3.0 \\
\text { Slurr } \\
\text { y }\end{array}$ & $\begin{array}{l}0.8 \\
1.7 \\
1.8 \\
1.8 \\
1.7 \\
\text { Slurry }\end{array}$ & $\begin{array}{l}0.8 \\
\\
2.5 \\
2.8 \\
3.0 \\
2.9 \\
\text { Slurry }\end{array}$ & $\begin{array}{l}0.8 \\
\\
1.6 \\
1.9 \\
1.7 \\
1.5 \\
\text { Slurry }\end{array}$ \\
\hline PETROL & $\begin{array}{l}\text { Initial } \\
\text { weight (g) } \\
@ 2 \mathrm{hrs} \\
\text { @ } 4 \mathrm{hrs} \\
\text { @ } 6 \mathrm{hrs} \\
\text { @ } 8 \mathrm{hrs} \\
\text { @ } 24 \mathrm{hrs}\end{array}$ & \begin{tabular}{l|l|}
0.7 \\
\\
1.4 \\
1.8 \\
1.5 \\
1.4 \\
1.2
\end{tabular} & $\begin{array}{l}0.7 \\
2.9 \\
3.5 \\
3.7 \\
3.7 \\
3.5\end{array}$ & \begin{tabular}{l|l|}
0.7 & \\
& \\
1.4 & 1.6 \\
1.9 & \\
1.8 & \\
1.6 &
\end{tabular} & \begin{tabular}{l|}
0.7 \\
1.7 \\
1.9 \\
2.0 \\
2.0 \\
1.9
\end{tabular} & $\begin{array}{l}0.7 \\
1.9 \\
1.9 \\
2.1 \\
1.9 \\
1.9\end{array}$ \\
\hline
\end{tabular}

\section{CONCLUSION}

From all the results obtained, it was deduced that carbon black is a better reinforcing filler compared to hydroxylated blended sugarcane bagasse while hydroxylated sugarcane bagasse is better reinforcing filler compared to unmodified blended sugarcane bagasse. The results also show the compatibility of the unmodified and hydroxylated sugarcane bagasse with natural rubber and carbon black.

\section{ACKNOWLEDGEMENT}

The authors are grateful to the entire staff of the Chemistry Department, Federal University of Agriculture, Abeokuta for putting their laboratory facilities down for our use, staff of Textile and Polymer Technology Department, Yaba College of Technology and Staff of Centre for Energy and Research Development, Obafemi Awolowo University, Ile-Ife.

\section{REFERENCES}

1 Akinlabi A.K., Okeimen F.E., Okwu U.N., Oladoja N.A. (2007). Journal of Applied Polymer Science, Wiley Interscience. 104 (5) 2830

2 A.K.Akinlabi., Okiemien,F.E and Aigbodion, A.I., Diffusion and Permeability of Aldehydes into Blends of Natural and Chemically Modified Low Molecule Weight Natural Rubber. (2005). Polymer for Advanced Technology. 16: 1-5

3 F.E. Okieimen, A.K. Akinlabi, A.I. Aigbodion, I.O. Bakare.J.Polym. Mat. (2003). Processing characteristics and physic-mechanical properties of thioglycollic acid modified epoxidised low molecular weight natural rubber and its blends with natural rubber. 20 (4), pg, 403-408.

4 E.J.Asore "An Introduction to Rubber Technology" First Edition, Josen Books, Benin City, (2000). 
5. Babbit R.O.\& Editer, Vanderbilt Rubber Handbook, R.T.Vanderbilt Company, Norwalk.Conn, (1978).

6. Brennan J.J, Jermyn T.E. (1965). Properties of black reinforced blends of natural rubber and butadiene rubber. J. Applied .Sci. 9: 27-45.

7. Determination of Mechanical Properties of Rubber Compounds; ASTM D 412-87; American Society for Testing and Materials: West Conshohocken, PA, 1992.

8. Method for Determination of Hardness; (1995). BS 903 Part A26. Wallace, Croydon, UK. Pg. 912.12

9. Egwaikhide, P.A., Akporhonor, E.E. and Okieimen, F.E. (2007).'Effect of fibre filler on the cure characteristics physico-mechanical and swelling properties of natural rubber

10. C. L. S. Baker, I. R. Gelling and R. Newell. RUBBER CHEM. TECHNOL. 58, 67 (1985).

11. Z. A. M. Ishak, A. A. Baker. Eur Polym. J. (1995). An the investigation on the potential of rice husk ash as fillers for epoxidized natural rubber (ENR). 31, pg. 259-269.

12. Okieimen F. E. and Imanah J. E. (2003). 'The characterization of agricultural waste product as filler in NR formulations.'Nigerian Journal Of Polymer Science And Technology 3(1), 178-240 